\title{
EFFECT OF DIFFERENT ENAMEL SURFACE PREPARATIONS ON THE MICRO-TENSILE BOND STRENGTH OF RESIN COMPOSITE TO BLEACHED ENAMEL
}

\author{
Mohamed F. Haridy ${ }^{*}$, Hend S. Ahmed ${ }^{* *}$ and Nermeen Kamal Hamza ${ }^{* * *}$
}

\begin{abstract}
Aim: This study was carried out to investigate the effect of different enamel surface treatments on micro-tensile bond strength of resin composite to bleached enamel

Materials and methods: 56 human premolars were used in this study. Teeth were divided into two main groups group 1: unbleached enamel (10 teeth) while group 2: bleached enamel (40 teeth). Then group 2 was subdivided into 4 subgroups (10 each) according the enamel surface treatment employed after bleaching and before bonding to composite either no treatment, grinding with diamond stone to remove $0.5 \mathrm{~mm}$ of the surface, air abrasion using the air abrasion system (AquaCare-Velopex International) and combination of grinding and air abrasion. Each subgroup as well as the control group was further divided into two classes (5 each) according to the aging time either 24 hours or 3 months. Another six specimens were used as representative for the enamel surface topography after treatments for scanning electron microscopy SEM testing. Specimens of group 2 were polished and mounted in an acrylic block (five teeth in each block) with slight lingual inclination from their long axis to facilitate bleaching and light application. For in office bleaching, Philips ZOOM in-office light-activated bleaching gel was used in this study. After the in-office bleaching, teeth were subjected to at home bleaching using Night White ACP system for successive 7 days. The bleached teeth were divided into four subgroups according the enamel surface treatment employed after bleaching and before bonding as mentioned before. All enamel specimens either unbleached (control) or bleached and prepared specimens were bonded to Filtek Universal Restorative composite (3M ESPE, St Paul, MN, USA) using Single Bond universal adhesive (3M ESPE, St Paul, MN, USA). For immediate subgroups and classes, the specimens were stored in distilled water for only $24 \mathrm{~h}$ after resin composite bonding. While for the three-month classes, the specimens were stored for three months in distilled water at room temperature. For micro-tensile bond strength test, specimens were longitudinally cut into a series of $1 \mathrm{~mm}$ thick slabs by means of a water-cooled diamond blade of thickness $0.5 \mathrm{~mm}$ in a low speed micro-slicing machine. By rotating the specimen $90^{\circ}$ and sectioning it again lengthwise (five cuts), four sticks of about $1 \mathrm{~mm}^{2}$
\end{abstract}

\footnotetext{
* Associate Professor of Conservative Dentistry, Faculty of Dentistry, Cairo University and British University in Egypt.

** Lecturer of Conservative Dentistry, Faculty of Dentistry, British University in Egypt

*** Lecturer of Conservative Dentistry, Faculty of Dentistry, October University for Modern Science and Art.
} 
in cross-section were obtained from the middle area of the tooth surface (20 specimens for each class). Each micro-tensile specimen was then glued with cyanoacrylate to the two free-sliding parts of the machine attachment. This jig is designed to transmit tensile forces to the specimen purely without any torque, and designed to fit the $\mu$ TBS Instron universal testing machine. The tensile load was applied at a cross-head speed of one $\mathrm{mm}$ /minute until specimen failure occurred. At this point the load at failure in Newtons was recorded. For surface topography evaluation, the representative specimens were prepared for SEM examination and photomicrograph at (x1000) were taken and stored digitally on the computer.

Results: Two-way ANOVA showed that the experimental variables 'enamel surface treatment' $(\mathrm{P}<0.0001)$ and 'ageing time' $(\mathrm{P}<0.0001)$ and their interaction $(\mathrm{P}<0.0001)$ had a statistically significant effect on $\mu$ TBS. One-way ANOVA and post-hoc Tukey's HSD test showed that either at 24 hours or 3 months, grinding and grinding/air abrasion combination yielded the significantly highest $\mu$ TBS $(\mathrm{P}<0.0001)$; followed by air abrasion. While, no enamel treatment produced the significantly lowest $\mu$ TBS $(\mathrm{P}<0.0001)$.

Conclusions: Within the limitations of the present study it can be concluded that:

1- The mTBS of resin composite decreases when applied immediately on bleached enamel

2- Technique of enamel surface preparations affects the mTBS of resin composite to the bleached enamel

3- Grinding of enamel with diamond stone to remove $0.5 \mathrm{~mm}$ or combination of grinding and air abrasion increases the mTBS of resin composite to bleached enamel than using air abrasion alone

4- Air abrasion of enamel surface after bleaching did not improve the mTBS of resin composite to bleached enamel.

5- mTBS of resin composite to bleached enamel decreases with 3 months aging when compared with that of 24 hours

\section{INTRODUCTION}

The constant search and demand for an esthetic, healthy and harmonious smile as well as the concerns by professionals in solving dental chromatic alterations have been increased in the last decades. Depending on the varied severity and types of discoloration, tooth color can be improved by tooth scaling and polishing, bleaching and veneers. Many other factors may affect human smile design such as form and position of teeth, meanwhile, in severely discolored malformed teeth it become the most challenging in deciding the most convenient treatment plan. Since we do not have a tool to diagnose or determine the depth of discoloration in enamel, combination of esthetic treatment modalities as, different bleaching techniques and protocols followed by direct or indirect veneers of different restorative materials that are bonded to intact or ground enamel may be done to obtain the maximum esthetic results. Although, bleaching has been proven to be relatively simple, allow relatively excellent results and preserve dental structure, it may present certain adverse effects on the enamel, such as surface morphological changes, compositional changes, alterations in the surface micro-hardness and surface roughness, also there is evidence that bleaching may lead to reduction in the bond strength of resin composite applied on previously bleached enamel $^{(1,2,3)}$.

Vital bleaching techniques include in-office technique, referred as power bleaching and at home bleaching. High concentration of hydrogen peroxide 
used in-office bleaching materials is accelerated by light sources as light emitting diode (LED), lasers and ultraviolet light (Zoom! Advanced). Bleaching agents accelerated by the LED, accelerates tooth bleaching in a way that, it improves bleaching agents' effectiveness and consequently decreases the chairside time. When bleaching agent mainly hydrogen peroxide comes in contact with the dental structure, it dissociates into free radicals such as nascent oxygen, and hydroxyl on the enamel surface. These radical/anion are highly reactive against the organic specimens underlying tooth staining, the so-called chromophores, which generally consist of long-chain molecules with double bonds and aromatic rings. These radicals act on these intrinsic stains by means of oxy-reduction reaction, a process by which macro-molecules of pigments are broken down into smaller molecules and they remain in the dental structure but no longer absorbs light ${ }^{(4,5)}$.

Regarding the reduction of bond strength of resin composite to immediately bleached enamel surface, it may be reduced up to 25-60\%. Although the mechanism is still not clear, the reduced bond strength of the bleached enamel has been related to the presence of residual free radicals due to the breakdown of hydrogen peroxide and alterations in the enamel composition and microstructure following the bleaching treatment. The residual oxygen in the inter-prismatic spaces can hamper resin infiltration and inhibit resin polymerization. Furthermore, morphological and compositional changes (eg. Porosity, loss of enamel prismatic form, loss of calcium and changes in organic substances) in the enamel may weaken the adhesive interface and compromise bond strength ${ }^{(6,7,8)}$. Therefore, bonding procedures should not be performed immediately after bleaching treatment. A waiting period of 1-3 weeks has been advocated by various researchers. In addition to the delayed bonding procedure the application of anti-oxidant agents (eg. Sodium ascorbate, sodium bicarbonate and the grape seed extract) and laser irradiation have been proposed to restore the compromised bond strength of bleached enamel ${ }^{(9,10,11)}$.

In cases of severely discolored dentition and the need for tooth shape correction, esthetic reconstructions, such as laminate and composite veneers, are often required after the bleaching treatment. Given the most negative effects of bleaching have been found on the enamel surface, it is conceivable that the veneer preparation process may remove the impacted enamel and further eliminate the compromised bond strength between the composite resin and bleached enamel ${ }^{(12)}$. In recent years, in addition to bur abrasive technique, air abrasion technique has been used for preparation of enamel surfaces. Air abrasion technique uses the kinetic energy of aluminum oxide particles for cutting and abrasion. It was firstly introduced by Robert Black in 1940 as an alternative to manual and rotary preparation. Air abrasion usually targets the tooth structure with high speed stream of purified aluminum oxide particles using air pressure. This technique has the advantages of no vibration, pressure or noise, also the formation of rough enamel surface; which is more suitable for bonding procedures. Tooth surface preparation by air abrasion removes small amounts of tooth structure and produces irregular cavity contours which is compatible with adhesive restorations ${ }^{(13)}$. However, it is important to point out that most of the studies measured the bond strength of composite resin to bleached enamel without aging, which is very important process for subjecting the restoration and tooth to different conditions simulating the oral environment. Therefore, in the present study aging of the specimens was done by storage in distilled water for 3 months. Therefore, the aim of the present study was to investigate the effect of different enamel surface treatments on the microtensile bond strength of resin composite to bleached enamel. The null hypothesis of this study was that the various enamel surface preparations would not affect the bond strength of resin composite to bleached enamel 


\section{MATERIALS AND METHODS}

\section{I-Teeth selection}

Freshly extracted human premolar teeth were used. Immediately after extraction, the teeth were scraped of any residual tissue, washed under running tap water and examined for presence of cracks. The selected teeth were stored in glass jars with distilled water at $4^{\circ} \mathrm{C}$ until used.

\section{II-Specimens grouping}

56 human premolars were used in this study. Teeth were divided into two main groups group 1: unbleached enamel (10 teeth) while group 2: bleached enamel (40 teeth). Then group 2 was subdivided into 4 subgroups (10 each) according the enamel surface treatment employed after bleaching and before bonding either no treatment, grinding with diamond stone, air abrasion and combination of grinding and air abrasion. Each subgroup as well as the control group was further divided into two classes (5 each) according to the aging time either 24 hours or 3 months. Six more specimens were used as representative for the enamel surface topography after treatments for scanning electron microscopy SEM testing.

\section{III-Enamel surface preparation}

Specimens of group 2 received the following treatments:

\section{III-a-Polishing of teeth}

Each tooth was hand held and pumiced for 5 seconds using slurry of pumice white rubber cup at a slow speed hand piece to simulate clinical situation

\section{III-b-Mounting of teeth}

The teeth were mounted in an acrylic block (five teeth in each block) with slight lingual inclination from their long axis to avoid bleaching gel seepage and facilitate light application.

\section{III-c-Bleaching technique}

\section{In office light activated bleaching}

Philips ZOOM in-office light-activated bleaching gel was used in this study. Bleaching agent was applied to the enamel surface according to manufacturer instructions. Philips Zoom White Speed LED device (Discus Dental LLC, Ontario, CA, USA) was used to activate the bleaching gel. Cap of Zoom Whitening Gel syringe was removed and mixing tip was attached by aligning markings then secured with 1/4 turn clockwise. A gel was applied on teeth (1-2 mm thick) and spread over the surface using brush provided with the kit. Light Guide was attached to the device lamp. Lamp was turned on (Wavelength $=465 \mathrm{~nm}$ ) and directed as close as possible to the teeth fixed in the acrylic block to activate the gel. The bleaching cycle was of fifteen minutes then the light was automatically turned off. The gel was removed using cotton roll without rinsing with water. The bleaching cycle was repeated three times with a total time of 45 minutes.

\section{Home bleaching}

After the in-office bleaching, teeth were subjected to at home bleaching using Night White ACP system. A twin-tube syringe with an automixing tip was used to supply this bleaching agent. A customized vinyl tray was constructed to fit the teeth fixed in the acrylic block with one-millimeter reservoir on the buccal surface. A one-millimeterthick layer of the bleaching gel was applied on the fitting surface of the tray then applied on the buccal surface of the teeth and left for two hours then the gel was removed using cotton roll and the specimens were washed with water and stored in distilled water till the next application. This procedure was repeated for successive 7 days.

\section{IV-Surface preparation of bleached enamel}

The bleached teeth were divided into four subgroups according the enamel surface treatment employed after bleaching and before bonding as follows: 
TABLE (1) Specifications of materials, composition and manufacturers

\begin{tabular}{|c|c|c|c|}
\hline Material & Specifications & Composition & Manufacturer \\
\hline Philips ZOOM & $\begin{array}{l}\text { In-office (chair-side) } \\
\text { light-activated bleach- } \\
\text { ing gel }\end{array}$ & $\begin{array}{l}\text { 25\% Hydrogen Peroxide and Ferrous Gluconate photo- } \\
\text { catalyst }\end{array}$ & $\begin{array}{l}\text { Discus Dental, } \\
\text { LLC., Ontario, } \\
\text { CA, } 91761 \text { USA }\end{array}$ \\
\hline $\begin{array}{l}\text { Philips Zoom Nite } \\
\text { White }\end{array}$ & $\begin{array}{l}\text { Home chemical acti- } \\
\text { vated bleaching gel } \\
\text { professional take-home } \\
\text { whitening system }\end{array}$ & $\begin{array}{l}22 \% \text { Carbamide Peroxide } \\
\text { formulated with ACP (amorphous calcium phosphate), } \\
\text { potassium nitrate and fluoride. }\end{array}$ & $\begin{array}{l}\text { Discus Dental, } \\
\text { LLC., Ontario, } \\
\text { CA, } 91761 \text { USA }\end{array}$ \\
\hline $\begin{array}{l}\text { Single bond uni- } \\
\text { versal }\end{array}$ & $\begin{array}{l}\text { Universal Total and } \\
\text { self-etch adhesive }\end{array}$ & $\begin{array}{l}\text { MDP Phosphate Monomer, Dimethacrylate resins, } \\
\text { HEMA VitrebondTM Copolymer, Filler, Ethanol, Wa- } \\
\text { ter, Initiators \& Silane. }\end{array}$ & $\begin{array}{l}\text { 3M ESPE, St } \\
\text { Paul, MN, USA }\end{array}$ \\
\hline $\begin{array}{l}\text { Filtek Universal } \\
\text { Restorative }\end{array}$ & $\begin{array}{l}\text { Universal restorative } \\
\text { resin composite }\end{array}$ & $\begin{array}{l}\text { The fillers are a combination of a non-agglomerated/ } \\
\text { non-aggregated } 20 \mathrm{~nm} \text { silica filler, a non-agglomerated/ } \\
\text { non-aggregated } 4 \text { to } 11 \mathrm{~nm} \text { zirconia filler, an aggregated } \\
\text { zirconia/silica cluster filler (comprised of } 20 \mathrm{~nm} \\
\text { silica and } 4 \text { to } 11 \mathrm{~nm} \text { zirconia particles), and a ytterbium } \\
\text { trifluoride filler consisting of agglomerated } 100 \mathrm{~nm} \\
\text { particles. The inorganic filler loading is about } 76.5 \% \\
\text { by weight ( } 58.4 \% \text { by volume). Filtek Universal Restor- } \\
\text { ative contains AUDMA, AFM, diurethane-DMA, and } \\
\text { 1,12-dodecane-DMA. }\end{array}$ & $\begin{array}{l}\text { 3M ESPE, St } \\
\text { Paul, MN, USA }\end{array}$ \\
\hline
\end{tabular}

Subgroup 1: no treatment, the enamel surface was left intact

Subgroup 2: grinding with diamond stone, the occlusal $2 / 3$ of buccal surface was lightly ground using water-cooled depth cut stones (Brassler, Savannah, Georgia, USA) of $0.5 \mathrm{~mm}$ depth and about $0.5 \mathrm{~mm}$ of the surface enamel was removed using water-cooled diamond no. 848 medium (Brassler, Savannah, Georgia, USA) to expose the sub-surface enamel; the gingival $1 / 3$ was not ground to avoid dentin exposure.

Subgroup 3: air abrasion; the air abrasion system used in this study was (AquaCare- Velopex International) that was adjusted at 60 psi particle energy, $53 \mu \mathrm{m}$ mean aluminum oxide particle size, 5 $\mathrm{g} / \mathrm{min}$ jet intensity, 20-s application, $10 \mathrm{~mm}$ distance and 90-degree impingement angle. The particle reservoir was frequently agitated to homogenize the size distribution.

Subgroup 4: combination of grinding followed by air abrasion.

\section{V-Direct resin composite build up}

All enamel specimens either unbleached (control) or bleached and prepared specimens were bonded to resin composite.

\section{V-a-Adhesive application}

A total etch adhesive system (Single Bond universal, 3M ESPE, St Paul, MN, USA) was used according to manufacturer's instructions. Etching of enamel surface was done by application of 30\% phosphoric acid (Scotch-bond, 3M ESPE, St. Paul MN,USA) for 30 seconds. The etchant gel was rinsed with air/water spray for 15 seconds. The surface was air-dried for 5 seconds and two consecutive coats of the adhesive were placed on the etched surface using a fully saturated micro-brush for each coat. The adhesive was gently air thinned for 10 seconds and then light cured for 20 seconds using LED light curing unit (Elipar S10, 3M ESPE, St Paul, MN, USA) operating in standard mode at light intensity $1200 \mathrm{~mW} / \mathrm{cm}^{2}$. The light intensity was periodically 
checked with the light meter integrated in the hand piece holder of the curing unit.

\section{V-b-Resin composite application}

Filtek Universal Restorative (3M ESPE, St Paul, MN, USA) shade A2 was applied to the bonded enamel surface according to manufacturer's instructions. For micro-tensile bond strength test specimens, a block of about $4 \mathrm{~mm}$ in height was created by incremental addition of 2-mmthick increments of the material using gold plated composite applicator; each increment was cured for 20 seconds with the same curing unit.

\section{VI-Aging of specimens}

For immediate subgroups and classes, the specimens were stored in distilled water for only $24 \mathrm{~h}$ after resin composite bonding. While for the three-month classes, the specimens were stored for three months in distilled water at room temperature, and the water was changed every week to prevent bacterial growth.

\section{VII-Micro-tensile bond strength testing test}

For micro-tensile bond strength test, each tooth with the bonded composite block was fixed on a plastic platform with low-fusing compound and longitudinally cut into a series of $1 \mathrm{~mm}$ thick slabs by means of a water-cooled diamond blade of thickness $0.5 \mathrm{~mm}$ (MTI Corporation, Richmond, CA, USA) in a low speed micro-slicing machine (Isomet, Buehler, Lake Bluff, IL, USA). By rotating the specimen $90^{\circ}$ and sectioning it again lengthwise (five cuts), four sticks of about $1 \mathrm{~mm}^{2}$ in crosssection were obtained from the middle area of the tooth surface (20 specimens for each class). Each stick consisted of tooth structures (enamel and dentin) for about a half of its length and the bonded restoration for the remaining portion. The interface of the specimens was inspected with $3.5 \mathrm{x}$ magnification loupe (Univet, Italy) for its quality (i.e., no voids or bubbles at the interface). Each micro-tensile specimen was then glued with cyanoacrylate (Zapit, DVA, Anaheim, CA, USA) to the two free-sliding parts of the machine attachment.
This jig is designed to transmit tensile forces to the specimen purely without any torque, and designed to fit the $\mu$ TBS Instron universal testing machine (Bisco Inc. Schaumburg, IL, USA). The tensile load was applied at a cross-head speed of one $\mathrm{mm} /$ minute until specimen failure occurred. At this point the load at failure in Newtons was recorded, and the specimen's fragments cautiously removed from the grips with a scalpel. If any specimen was observed to have the cyanoacrylate glue reach the interface, the specimen was discarded because the bond strength would not have been represented correctly. The cross-sectional area at the site of fracture was measured to the nearest $0.01 \mathrm{~mm}$ with a digital caliper, in order to calculate the bond strength at failure in Mega-Pascals (MPa).

\section{VIII-Scanning Electron Microscopy (SEM) evaluation}

For surface topography evaluation, the representative specimens were prepared for SEM examination by dehydration in an ascending series of ethanol and critical point-dried for 10 minutes then they were gold-sputter-coated (EMS-76M; Earnest F) and evaluated under a SEM (Hitachi S-2500, Hitachi High Tech, Tokyo, Japan) at different magnifications. Photomicrograph at (x1000) were taken and stored digitally on the computer.

\section{Statistical analysis}

Statistical analysis was performed using IBM SPSS Statistics Version 2.0 for Windows. Data was presented as mean and standard deviation (SD). The significance level was set at $\mathrm{P} \leq 0.05$. KolmogorovSmirnov and Shapiro-Wilk tests were used to assess data normality. Two-way ANOVA was used to evaluate the effect of the experimental variables and their interaction on $\mu$ TBS. Pair-wise comparisons between different enamel surface treatments at each ageing time were performed using One-way ANOVA and post-hoc Tukey's HSD test. Dunnett's test was used to compare between the control group and the enamel surface treatment groups. Intergroup comparisons regarding ageing time within the control group and each enamel surface treatment were conducted using Independent Student-t test. 
TABLE (2): Two-way ANOVA for the effect of investigated variables on microtensile bond strength.

\begin{tabular}{|c|c|c|c|c|c|}
\hline Source & Type III Sum of Squares & df & $\begin{array}{c}\text { Mean } \\
\text { Square }\end{array}$ & F & Sig. \\
\hline Corrected model & $2143.008^{\mathrm{a}}$ & 7 & 306.144 & 138.261 & $<0.0001^{*}$ \\
\hline Intercept & 26714.374 & 1 & 26714.374 & 12064.751 & $<0.0001^{*}$ \\
\hline Enamel surface treatment & 1754.793 & 3 & 584.931 & 264.167 & $<0.0001^{*}$ \\
\hline Ageing time & 380.175 & 1 & 380.175 & 171.695 & $<0.0001^{*}$ \\
\hline Enamel surface treatment x Ageing time & 8.040 & 3 & 2.680 & 1.210 & 0.314 \\
\hline Error & 123.998 & 56 & 2.214 & & \\
\hline Total & 28981.380 & 64 & & & \\
\hline Corrected total & 2267.006 & 63 & & & \\
\hline
\end{tabular}

\section{RESULTS}

Two-way ANOVA (Table 2) showed that the experimental variables 'enamel surface treatment' $(\mathrm{P}<0.0001)$ and 'ageing time' $(\mathrm{P}<0.0001)$ and their interaction $(\mathrm{P}<0.0001)$ had a statistically significant effect on $\mu$ TBS.

One-way ANOVA and post-hoc Tukey's HSD test (Table 3 and Figure 1) showed that either at 24 hours or 3 months, grinding and grinding/air abrasion combination yielded the significantly highest $\mu$ TBS $(\mathrm{P}<0.0001)$; followed by air abrasion. While, no enamel treatment produced the significantly lowest $\mu$ TBS $(\mathrm{P}<0.0001)$.

TABLE (3): Mean \pm SD and P-value for the effect of enamel surface treatment on microtensile bond strength $(\mathrm{MPa})$ to bleached enamel at each ageing time.

\begin{tabular}{|l|c|c|}
\hline & 24 hours & 3 months \\
\hline No treatment & $14.19 \pm 20.9^{\mathrm{c}}$ & $9.27 \pm 1.31^{\mathrm{c}}$ \\
\hline Grinding & $27.03 \pm 1.09^{\mathrm{a}}$ & $21.86 \pm 1.44^{\mathrm{a}}$ \\
\hline Air abrasion & $22.77 \pm 1.32^{\mathrm{b}}$ & $19.03 \pm 1.87^{\mathrm{b}}$ \\
\hline Grinding/Air abrasion & $27.47 \pm 1.12^{\mathrm{a}}$ & $21.79 \pm 1.30^{\mathrm{a}}$ \\
\hline P-value & $<0.0001^{*}$ & $<0.0001^{*}$ \\
\hline
\end{tabular}

Means with identical superscript lowercase letters within the same column are not statistically significantly different at $P \leq 0.05$.

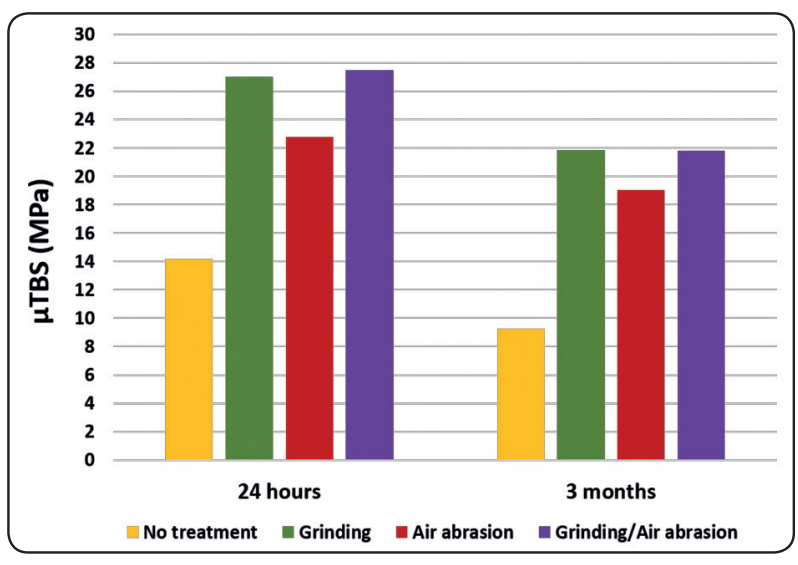

Fig. (1): Bar chart showing the effect of enamel surface treatment on microtensile bond strength $(\mathrm{MPa})$ to bleached enamel at each ageing time.

Dunnett's test (Table 4 and Figure 2) showed that at 24 hours, the $\mu$ TBS mean value of control group was statistically significantly higher than those of enamel surface treatment groups. At 3 months (Table 5 and Figure 2), the $\mu$ TBS mean value of control group was statistically significantly higher than those of no treatment and air abrasion groups. While, there were no statistically significant differences between the $\mu$ TBS mean value of control group and those of grinding and grinding/air abrasion combination groups. 
TABLE (4): Comparison between $\mu$ TBS mean values of control group and enamel surface treatment groups at 24 hours.

\begin{tabular}{|c|c|c|c|}
\hline \multirow{2}{*}{24 hours } & $\begin{array}{c}\text { Surface } \\
\text { treatment }\end{array}$ & Mean \pm SD & P-value \\
\hline & No treatment & $14.19 \pm 20.9$ & $<0.0001^{*}$ \\
\cline { 2 - 4 } Control & Grinding & $27.03 \pm 1.09$ & $0.024^{*}$ \\
\cline { 2 - 4 } $28.71 \pm 1.21$ & Air abrasion & $22.77 \pm 1.32$ & $<0.0001^{*}$ \\
\cline { 2 - 4 } & $\begin{array}{c}\text { Grinding/Air } \\
\text { abrasion }\end{array}$ & $27.47 \pm 1.12$ & $0.020^{*}$ \\
\hline
\end{tabular}

$*: P \leq 0.05$

Table (5): Comparison between $\mu$ TBS mean values of control group and enamel surface treatment groups at 3 months.

\begin{tabular}{|c|c|c|c|}
\hline \multirow{3}{*}{3 months } & $\begin{array}{c}\text { Surface } \\
\text { treatment }\end{array}$ & Mean \pm SD & P-value \\
\hline \multirow{3}{*}{$\begin{array}{c}\text { Control } \\
23.94 \pm 1.22\end{array}$} & No treatment & $9.27 \pm 1.31$ & $<0.0001^{*}$ \\
\cline { 2 - 4 } & Grinding & $21.86 \pm 1.44$ & $0.073^{*}$ \\
\cline { 2 - 4 } & $\begin{array}{c}\text { Grinding/Air } \\
\text { abrasion }\end{array}$ & $21.79 \pm 1.30$ & 0.249 \\
\hline
\end{tabular}

\section{$*: P \leq 0.05$}

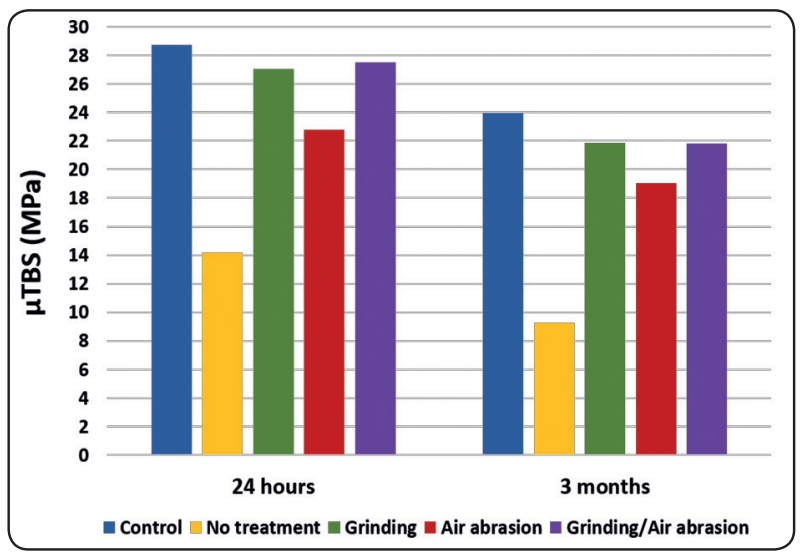

Fig. (2): Bar chart showing the comparison between the control group and the enamel surface treatment groups enamel at each ageing time.
Independent Student-t test (Table 6 and Figure 3) revealed that within all study groups, $\mu$ TBS mean values at 24 hours were statistically significantly higher than those at 3 months.

TABLE (6): Mean \pm SD and P-value for the effect of ageing time on microtensile bond strength (MPa) to unbleached and bleached enamel.

\begin{tabular}{|l|c|c|c|}
\hline & 24 hours & 3 months & P-value \\
\hline Control & $28.71 \pm 1.21$ & $23.94 \pm 1.22$ & $<0.0001^{*}$ \\
\hline No treatment & $14.19 \pm 20.9^{\mathrm{c}}$ & $9.27 \pm 1.31^{\mathrm{c}}$ & $<0.0001^{*}$ \\
\hline Grinding & $27.03 \pm 1.09^{\mathrm{a}}$ & $21.86 \pm 1.44^{\mathrm{a}}$ & $<0.0001^{*}$ \\
\hline Air abrasion & $22.77 \pm 1.32^{\mathrm{b}}$ & $19.03 \pm 1.87^{\mathrm{b}}$ & $<0.0001^{*}$ \\
\hline $\begin{array}{l}\text { Grinding/Air } \\
\text { abrasion }\end{array}$ & $27.47 \pm 1.12^{\mathrm{a}}$ & $21.79 \pm 1.30^{\mathrm{a}}$ & $<0.0001^{*}$ \\
\hline
\end{tabular}

\section{$* \cdot P \leq 0.05$}

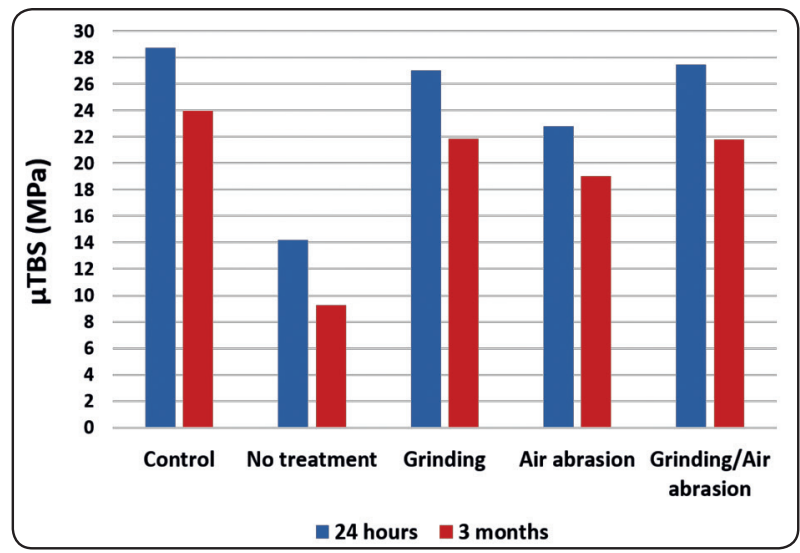

Fig. (3): Bar chart showing the effect of ageing time on microtensile bond strength (MPa) to unbleached and bleached enamel.

\section{Scanning electron microscopy (SEM)}

The photomicrograph of the sound untreated specimens showed flat and relatively smooth surface with some shallow striations figure (4). After grinding with diamond stone the surface of enamel was covered with a smear layer and multiple cutting scars figure (5). The photomicrograph of the air abraded enamel showed unaffected and relatively smooth surface with characteristic smear layer figure (6). The combination of grinding and air abrasion showed scared surface and islands of smear layer figure (7). 


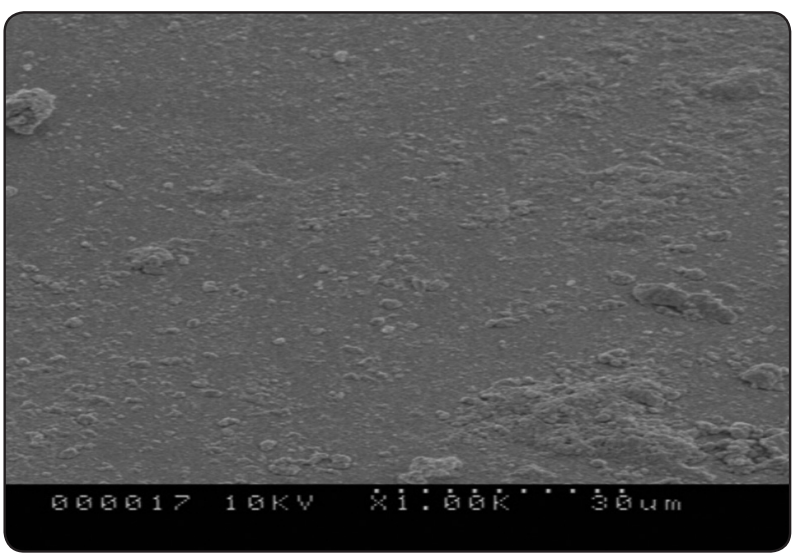

Fig. (4): SEM photomicrograph (x1000) of sound enamel (control)

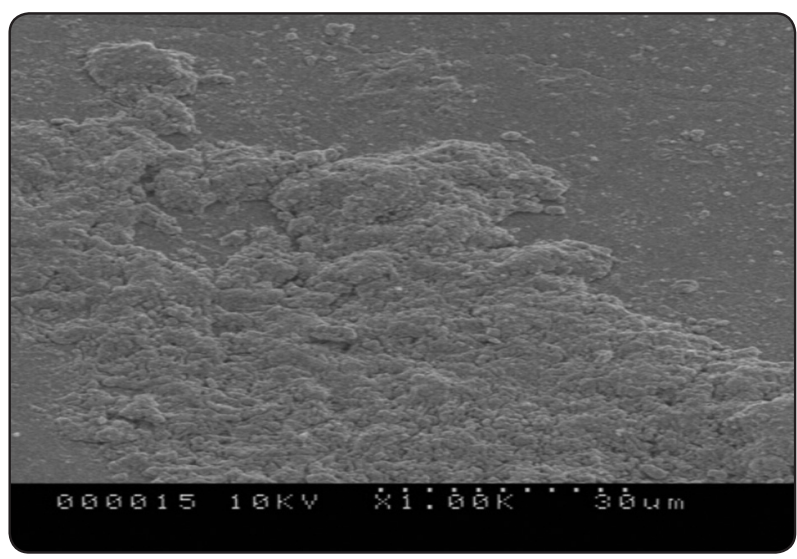

Fig. (6): SEM photomicrograph (x1000) of air abraded enamel

\section{DISCUSSION}

For maximum esthetic results, more than one treatment modality may be used. Recently, the bleaching procedure followed by laminate veneers are very common line of treatment to obtain the best results for patient satisfactory if one treatment modality did not improve the color sufficiently. Several materials and methods of bleaching procedure are used nowadays, as it is easy and more conservative way of treating discolored teeth. In some cases, combination of the in-office bleaching and at home bleaching may be applied to get the maximum effect of teeth whitening, especially in the severely discolored teeth ${ }^{(12)}$. In the present study combination of both techniques was used; the in-

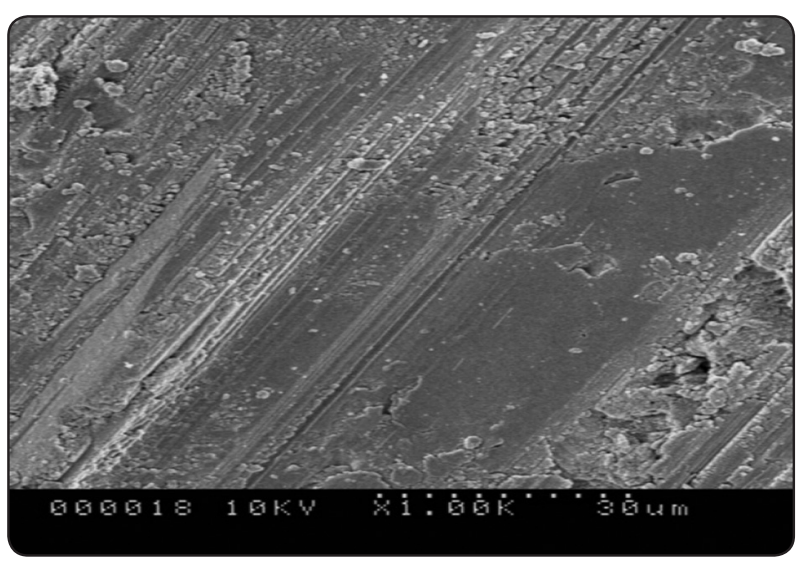

Fig. (5): SEM photomicrograph (x1000) of ground enamel

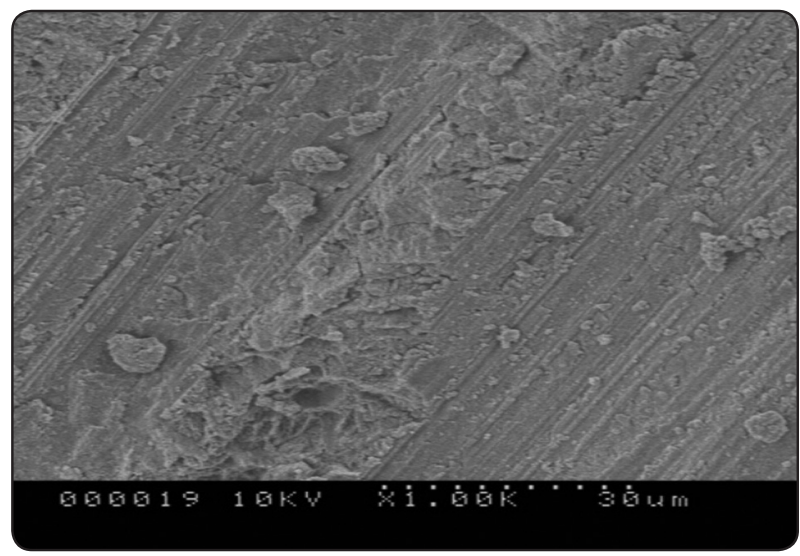

Fig. (7): SEM photomicrograph (x1000) of ground and air abraded enamel

office bleaching (ZOOM using LED) followed by at-home bleaching (ZOOM Nite White containing ACP). Furthermore, veneering of malformed and maligned teeth is considered one of the most conservative line of treatment, in which they may require minimal tooth preparation or not.

The effect of bleaching agents on both dental tissues and composite resin bond strength have been described in numerous studies. However, the ways to minimize or reverse the undesirable effects are still under study, and there is currently much concern in determining the best way to perform esthetically successful clinical procedures while at the same time providing biological safety, reducing the side effects during and after treating dental tissues and dental 
materials. For this reason, more studies are required to substantiate alternative protocols to improve the prognosis of adhesive restorations after bleaching. Therefore, the aim of the present study to compare the micro-tensile bond strength of unbleached and bleached enamel after a surface removal of $0.5 \mathrm{~mm}$, which was performed to simulate tooth preparation process for a indirect or direct composite veneers, by using different ways of surface treatment.

In the present study, one total-etch bonding system (single bond universal) and one type of composite resin (Filtek Universal) were used to exclude the bonding system and type of restoration as a variable. Concerning the effect of enamel grinding after bleaching, it was of value to assess the penetration depth of the bleaching agent. Therefore, $0.5 \mathrm{~mm}$ of enamel surface was removed in all specimens to standardize the thickness of enamel removal in this study with different techniques of removal. In the current study, regarding the effect of bleaching technique on the bond strength to enamel, the results showed that bleaching significantly decreased the mTBS of resin composite when bonded immediately to unground bleached enamel. These results compatible with those of Nour El Din 2006 and Unlu et al 2008. Previous studies have reported that dental bleaching procedure reduced the immediate bond strength of restorative materials to bleached enamel surface, which occurs due to the presence of residual oxygen produced by the bleaching agent. Hydrogen peroxide have been reported as the most effective and powerful oxidizing agent, the oxygen in the hydrogen peroxide is believed to be absorbed into the enamel and dentin, then it is released through the surface diffusion and accumulates within the enamel structure, causing inhibition of resin polymerization which affects the bond strength of composite resin to enamel. Furthermore, when hydrogen peroxide decomposes into oxygen and water, oxygen free radicals are released which cause changes in the $\mathrm{pH}^{(16,17)}$.
The presence of the residual oxygen might interfere with the resin infiltration into the enamel pores and resin of dental adhesive polymerization. As the setting reaction of the dental adhesives is based on generation of free radicals through light activated redox initiator that released oxygen due to breakdown of hydrogen peroxide, may become trapped within the adhesive during light activation leading to incomplete polymerization of the adhesive, with the formation of bubble-like voids along the enamel-resin interface. Furthermore, it inhibits the polymerization process by interrupting the formation of the three-dimensional net of the long polymer chain of methacrylate-based resins, reducing the degree of conversion as a consequence bond strength reduction will be performed as has been reported by Fatme Dilsad and Zeynap Bilge Kutuk 2018.

Another reason for the transient reduction in the bond strength immediately after bleaching is that it might be due to the chemical effects of the bleaching agents on enamel surface such as mineral loss and changes in calcium-phosphorous concentration ${ }^{(19,20)}$. These changes may affect the micro-hardness of enamel surface that consequently change the bonding ability of the enamel. Furthermore, the oxidizing effect of peroxide radicals as well as by urea from carbamide peroxide bleaching agents may affect the organic matrix of enamel subsurface which might affect the mechanical properties of enamel such as fracture toughness and micro-hardness ${ }^{(4,21)}$. In the present study this effect may be diminished due to the use of home bleaching (ZOOM Nite White) which is carbamide peroxide containing ACP, in which, the calcium and phosphate ions which are released penetrate into the enamel rods, resulting in increase in the density of hydroxyapatite crystals. Thus, the presence of ACP in the home bleaching decreased the effect of the carbamide peroxide on the morphological changes that may occur in the enamel subsurface ${ }^{(22)}$.

Furthermore, the peroxide-containing bleaching agents affect the organic phase of enamel surface 
and may extend to the subsurface of enamel. These changes might be due to the natural permeability canals of enamel as prism sheaths, the intercrystalline matrix, Retzius striae, enamel lamellae or through porous areas produced by demineralization associated with the low $\mathrm{pH}$ associated with certain bleaching agents. Also, this penetration may be due to the low molecular weight of hydrogen peroxide, so it can penetrate deeply into enamel and may reach dentin and even pulp, the demineralization of enamel may extend to a depth of $50 \mathrm{~mm}$ below the enamel surfaces following bleaching. Other studies reported that bleaching treatment with in-office or home bleaching system had no effect on the bond strength of resin composite to the bleached enamel either immediately or when delayed after bleaching $(23,24,25,26)$. These results were in contradiction with the results of the present study.

Concerning the effect of enamel grinding following bleaching, the null hypothesis was rejected as the different surface treatment did affect the bond strength of the composite resin to immediately bleached enamel. In the present study there was significant increase in the mTBS after enamel surface removal using diamond stone and the combination of diamond stone and air abrasion which exhibited similar mTBS values to those of the control group (unbleached enamel). These results may be attributed to removal of the superficial layer of enamel surface that contains the residual oxygen which contains all chemical and morphological changes occurred. Also, removal of various thickness of enamel exposed the deeper layers of enamel that are more reactive to the adhesive layer. Kuhar et al in 1997, reported that enamel treatment by grinding and etching caused a significant increase in the enamel permeability as the adhesive infiltration is affected by enamel permeability; thus, grinding might increase the ability of low viscous adhesive to infiltrate in the ground-etched enamel surface increasing the bond strength of the resin composite to ground enamel. Meanwhile, the results of the present study revealed that using air abrasion in removal of enamel surface showed decrease in the mTBS when compared to the control group and the two other groups (diamond stone group and combination group), this may be due to that the continuous mode of air abrasion promoted slight abrasion on the enamel surface, which could be doubtful of uniform removal of $0.5 \mathrm{~mm}$ of enamel surface, as it was proved by Claudia et al 2013 that the pulsed mode facilitating the abrasive particles arrival on the dental surface to a higher speed even at a constant air pressure, possibly due to the interruption of the jet. However, it was concluded that the depth cutting capacity was increased by $62.11 \%$ when air abrasion was employed in the pulse mode, confirming that there is an increase in the dust flow or the speed particles in the pulse mode that enables cutting of the dental tissues in an incremental manner and with more efficiency than that of the continuous mode. Also, it was proven that with increased time there is an augmentation of damage of enamel crystals that may affect the bonding quality of enamel. These results were similar after 24 hours and 3 months aging, thus, the technique of enamel surface removal affects the micro-tensile bond strength of composite resin to the immediately bleached enamel surface.

Mahsid et al 2016 reported that the type of bonding adhesive system affect the bond strength following immediate bleaching without any surface treatment or surface removal, in which they attributed that ethanol-based adhesive system showed high bond strength to immediately bleached enamel, and this was explained that the alcohol content in this adhesive system could react with water and oxygen in superficial enamel layer and neutralize the effect of oxygen molecules retained from bleaching treatment. Also, the etch and rinse adhesive system with separate application of acid etching with superficial layer removal improved the bond strength in the bleached samples. These results were in contradiction with those of the present study in which the total-etch adhesive system used as well as bonding agent used in this study was 
ethanol-based showed the lowest bond strength to the immediate unground bleached enamel surface. Regarding these results, it might be due to the changes in the inter- and intra-prismatic structure caused by bleaching or by over etching due to bleaching followed by etching. This over etching leads to loss of surface micro-porosities needed for profound resin infiltration ${ }^{(14)}$.

Regarding aging of the specimens, results revealed that there was significant increase in the mTBS after 24 hours when compared with 3 months aging. Degradation of composite resin in the oral environment is attributed to the resin matrix, filler particles and hydrolytic instability of the silane coupling agent at the polymer-silica interface. Aging in distilled water is accompanied by water absorption that makes changes in mechanical and physical properties of resin composite. Also, water absorption and $\mathrm{pH}$ changes accredited breakdown of resin-silica bond between filler particles and resin, therefore, aged composite are more sensitive to load ${ }^{(27)}$. Therefore, the decrease of the mTBS after 3 months aging in distilled water cannot be attributed to the effect of bleaching agent applied on the enamel surface, as there are many other factors including the mechanical and physical properties of resin composite which may affect the mTBS.

Concerning the SEM which is fast and convenient method for qualitative analysis of tooth structure after different techniques of enamel surface removal following bleaching, SEM findings of the ground enamel using diamond stone showed multiple scars and irregularities with smear layer theses scars might increase the surface area for resin infiltration as well as the increased reactivity of the freshly exposed enamel subsurface ${ }^{(28)}$. Regarding the formed smear layer, in this study etch and rinse adhesive was used that ensure total removal of the smear layer with formation of more irregularities providing more resin tags formation and increased mTBS of the resin composite ${ }^{(29)}$. On the other hand, air abrasion of enamel surface revealed relatively no effect on the surface and less irregularities with impaired resin infiltration and decreased mTBS of the resin composite. Furthermore, on combination of both techniques; the mTBS of resin composite increased that might be attributed to the effect grinding as mentioned before.

Based on the mTBS results of the present study, bonding of composite resin immediately after bleaching could be done if $0.5 \mathrm{~mm}$ of the enamel surface is removed using diamond stone or combination of diamond stone and air abrasion, as it showed increased mTBS similar to that of unbleached enamel surface, while on using the air abrasion alone showed decreased mTBS when compared to other groups. Therefore, the negative effect of the bleaching agent on enamel surface could be reversed by preparation for laminate veneers in cases that need more than one treatment modality to obtain the best results of severely discolored teeth and with malformed and maligned teeth.

\section{CONCLUSIONS}

Within the limitations of the present study it can be concluded that:

1- The mTBS of resin composite decreases when applied immediately on bleached enamel

2- Technique of enamel surface preparations affects the mTBS of resin composite to the bleached enamel

3- Grinding of enamel with diamond stone to remove $0.5 \mathrm{~mm}$ or combination of grinding and air abrasion increases the mTBS of resin composite to bleached enamel than using air abrasion alone

4- Air abrasion of enamel surface after bleaching did not improve the mTBS of resin composite to bleached enamel.

5- mTBS of resin composite to bleached enamel decreases with 3 months aging when compared with that of 24 hours 


\section{REFERENCES}

1. Homayoon Alaghehmandi, Marzieh Rohaninassab, Ali Bijani. (2019) The effect of affice bleaching on color and bond strength of resin restoration. Dental research journal. $16(1) ; 47$.

2. Chen HP, Chang CH, Liu JK, Chuang SF, Yang JY. (2008) Effect of fluoride containing bleaching agents on enamel surface properties. J Dent.36:718-25.

3. Martin JM, de Almeida JB, Rosa EA, Soares P, Torno V, Rached RN, Mazur RF. (2010) Effect of fluoride therapies on the surface roughness of human enamel exposed to bleaching agents. Quintessence Int.41:71-8.

4. Cantídio Francisco de Lima Neto, Carolina Batista da Silva, Marcos Aurélio Bomfim da Silva, Rafael Pino Vitti Carmem Lúcia de Paiva e Silva ZantaJosealdo Tonholo. (2018) Tooth whitening affects bond strength of adhesive systems in enamel. Revista Materia Journal. 23 (4).

5. Lima DA, Aguiar FH, Pini NI, Soares LE, Martin AA, Liporoni PC, Ambrosano GM, Lovadino JR. (2015) In vitro effects of hydrogen peroxide combined with different activators for the in-office bleaching technique on enamel. Acta Odontol Scand. 73:516-21.

6. Lai SC, Tay FR, Cheung GS, Mak YF, Carvalho RM, Wei SH, Toledano M, Osorio R, Pashley DH. (2002) Reversal of compromised bonding in bleached enamel. J Dent Res. 81:477-81.

7. Vidhya S, Srinivasulu S, Sujatha M, Mahalaxmi S. (2011) Effect of grape seed extract on the bond strength of bleached enamel. Oper Dent.36:433-8.

8. Briso AL, Toseto RM, Rahal V, dos Santos PH, Ambrosano GM. (2012) Effect of sodium ascorbate on tag formation in bleached enamel. J Adhes Dent.14:19-23.

9. Minoux M, Serfaty R. (2008) Vital tooth bleaching: biologic adverse effects-a review. Quintessence Int. 39:645-59.

10. Turkun M, Celik EU, Kaya AD, Arici M. (2009) Can the hydrogel form of sodium ascorbate be used to reverse compromised bond strength after bleaching? J Adhes Dent. 11:35-40.

11. Kunt GE, Yilmaz N, Sen S, Dede DO. (2011) Effect of antioxidant treatment on the shear bond strength of composite resin to bleached enamel. Acta Odontol Scand. 69:287-91.
12. Yi-Ling Cheng, Joseph Musonda, Hui Cheng, Thomas Attin, Ming Zheng and Hao Yu. (2019) Effect of surface removal following bleaching on the bond strength of enamel. Bio. Med. Central Journal. 19 (50).

13. Claudia Peruchi, Ary Santos-Pinto, Tereza Cristina Dias, Ana Carolina Mascarenhas Oliveria and Lourdes SantosPinto. (2013) Influence of air abrasion tips and application of modes on enamel cutting characteristics. Eup. Journal of Dent. Vol 7, 1-5.

14. Nour El-din, A.K., Miller,B.H., Griggs, J.A. and Wakefield, C. (2006). Immediate bonding to bleached enamel. Oper. Dent. 31(1): 106-14.

15. Unlu, N., Cobankara, F.K.and Ozer, F. (2008). Effect of elapsed time following bleaching on the shear bond strength of composite resin to enamel. J Biomed Mater Res Biomater.84(2): 363-8.

16. Guler E, Gonulol N, Ozyilmaz OY, Yucel AC. (2013) Effect of sodium ascorbate on the bond strength of silorane and methacrylate composites after vital bleaching. Braz Oral Res. 27:299-304.

17. Bittencourt BF, Dominguez JA, Loguercio AD, Gomes JC, Gomes OM. (2013) Influence of two different methods of delivering fluoride on bond strength and degree of conversion of an adhesive after bleaching. J Adhes Dent.;15:553-9.

18. Fatma Dilsad Oz and Zeynap Bilge kutuk. (2018) Effect of various bleaching treatments on shear bond strength of different universal adhesives and application modes. Rest. Dent. And Endo. Journal43 (2); 20.

19. Efeoglu, N., Wood, D. and Efeoglu, C. (2005). Microcomputerised tomography evaluation of $10 \%$ carbamide peroxide applied to enamel. J Dent (33):561-67.

20. Efeoglu, N., Wood, D.J. and Efeoglu, C. (2007). Thirtyfive percent carbamide peroxide application causes in vitro demineralization of enamel. Dent Mater. 23(7):900-4.

21. Paula Alejandra Baldion Ebrza. (2013) Influence of postbleaching time on composite resin bond strength to enamel. Vol. 25 (1).

22. Reham M. Attia and Mohamed M. Kamal. (2016) Changes in surface roughness of bleached enamel by using different remineralizing agents. 13 (4); 179-186.

23. Cavalli, V., Arrais, C.A., Giannini, M. and Ambrosano, G.M. (2004). High concentrated carbamide peroxide bleaching agents' effects on enamel surface. J Oral Rehab. 31(2): 155-9. 
24. Bishara, S.E., Oonsombat, C., Soliman, M.M., Ajlouni, R. and Laffoon, J.F.(2005). The effect of tooth bleaching on the shear bond strength of orthodontic brackets. Am J Orthod Dentofacial Orthop. 128(6):755-60.

25. da Silva Machado, J., Cândido, M.S., Sundfeld, R.H., De Alexandre, R.S., Cardoso, J.D.and Sundefeld ML. (2007). The influence of time interval between bleaching and enamel bonding. J Esthet Restor Dent. 19(2): 111-8.

26. Mielczarek, A., Klukowska, M., Ganowicz, M., Kwiatkowska, A. and Kwaśny, M. (2008). The effect of strip, tray and office peroxide bleaching systems on enamel surfaces in vitro. Dent Mater. 24(11): 1495-500.
27. Milan Kuhar, Pavel Cevc, B. Milan, Nena Fundek (1997). Enhanced permeability of acid etched or ground dental enamel. Journal of Prosthet. Dentistry. Vol 77 (6).

28. Horieh Moosav, Hamideh Sadat Mohammadipour, Marjaneh Ghavamnasiri and Sanaz Alizadeh. (2016) Effect of Bleaching and Thermocycling on Resin-Enamel Bond Strength. Int. Jour. Of Biomaterials. Vol 10 (8); ZC44-ZC47.

29. Mahshid Mohammadi Basir, Mohammad Bagher Rezvani, Nasim Chiniforush'Zohreh Moradi (2016) Effect of $\mathrm{CO}_{2}$, Nd: YAG and Er: YAG Lasers on Microtensile Bond Strength of Composite to Bleached-Enamel. Open Dent. Journal. Vol. 10; 148-157. 